\title{
Physicochemical Assessment of Stirred Yogurt Enriched with Mofarrah (Nepeta crispa Wild)
}

\author{
Reyahi-Khoram Reihaneh ${ }^{1 *}$, Daraei-Garmakhani Amir', \\ Kalvandi Ramazan ${ }^{3}$, and Reyahi-Khoram Mahdi ${ }^{4}$ \\ ${ }^{1}$ Department of Food Sciences \& Technology, Faculty of Advanced Sciences \& Technology, \\ Pharmaceutical Sciences Branch, Islamic Azad University, Tehran, Iran \\ ${ }^{2}$ Department of Food Science and Technology, Toyserkan Faculty of Industrial Engineering, \\ Bu-Ali Sina University, Hamedan, Iran \\ ${ }^{3}$ The Center of Agriculture Research and Education and Natural Resources, Hamedan, Iran \\ ${ }^{4}$ Department of Environmental Sciences, Faculty of Basic Sciences, Hamedan Branch, Islamic \\ Azad University, Hamedan, Iran \\ *Corresponding author.E-mail: rriahik@gmail.com \\ https://doi.org/10.12982/CMUJNS.2018.0017
}

\begin{abstract}
Nepeta crispa Wild is an aromatic plant endemic to Iran; locally known as Mofarrah, it has been widely used in traditional medicine. The objective of this study was to enrich yogurt with various concentrations of dry Nepeta crispa and evaluate the effects on its physicochemical properties and sensory characteristics. The aerial parts (leaf, flower, and stalk) of Nepeta crispa Wild were collected from three sampling stations in Hamedan Province, Iran. The collected samples were cleaned and crushed to obtain fine powders and flakes that were mixed with stirred yogurt at different ratios $(0.25 \%, 0.5 \%$, and $0.75 \% \mathrm{w} / \mathrm{w})$. Five quality parameters - acidity, moisture, $\mathrm{pH}$, fat, and salt - of the Mofarrah-enriched yogurt were measured. A sensory panel also evaluated the samples for sensory acceptability. The results showed that the mean acidity, $\mathrm{pH}$, moisture, salt, and fat varied significantly $(P<0.05)$ between the enriched yogurt and control samples. The enriched samples were all of acceptable sensory quality.
\end{abstract}

Keywords: Environment, Food, Natural product, Plant nutrition 


\section{INTRODUCTION}

Aromatic plants have been incorporated into food to impart flavor, taste, and color. Many of these aromatic plants and their products have diverse antimicrobial activities (Zomorodian et al., 2013). Nepeta crispa Wild (locally known as Mofarrah, or 'sweet odor') is a prominent aromatic plant endemic to Iran widely used in Iranian folk and traditional medicine, particularly in Hamedan Province. The aerial parts (leaf, flower, and stalk) of Nepeta crispa have been used in infusions, herbal syrup, and beverages as a restorative tonic for nervous, carminative, relaxant, sedative, and respiratory disorders (Sonboli et al., 2004). Ahmadvand et al (2015), in a comparative study in Lorestan Province, Iran, obtained hydroalcoholic extracts and essences of Nepeta crispa and assessed their antioxidant properties.

Many studies have reported on probiotic dairy products as functional foods. Some combined probiotic stirred yogurts with glucose oxidase (Cruz et al., 2012; Cruz et al., 2013; Aline et al., 2015). Another reported that combining yogurt with selected aromatic vegetables provided a variety of fibers, vitamins, and minerals and improved health, including through its antioxidant properties (Ahmadvand et al, 2015). Although yogurt is the most popular dairy product in Iran (Mohamadshahi et al., 2014) and Mofarrah one of the most useful indigenous plants, no study has assessed the physicochemical and sensory qualities of Mofarrah-enriched yogurt. The objective of this study was to fortify yogurt with various concentrations of dry Nepeta crispa, or Mofarrah, and evaluate the effects of the plant on the physicochemical and sensory characteristics of the enriched yogurt.

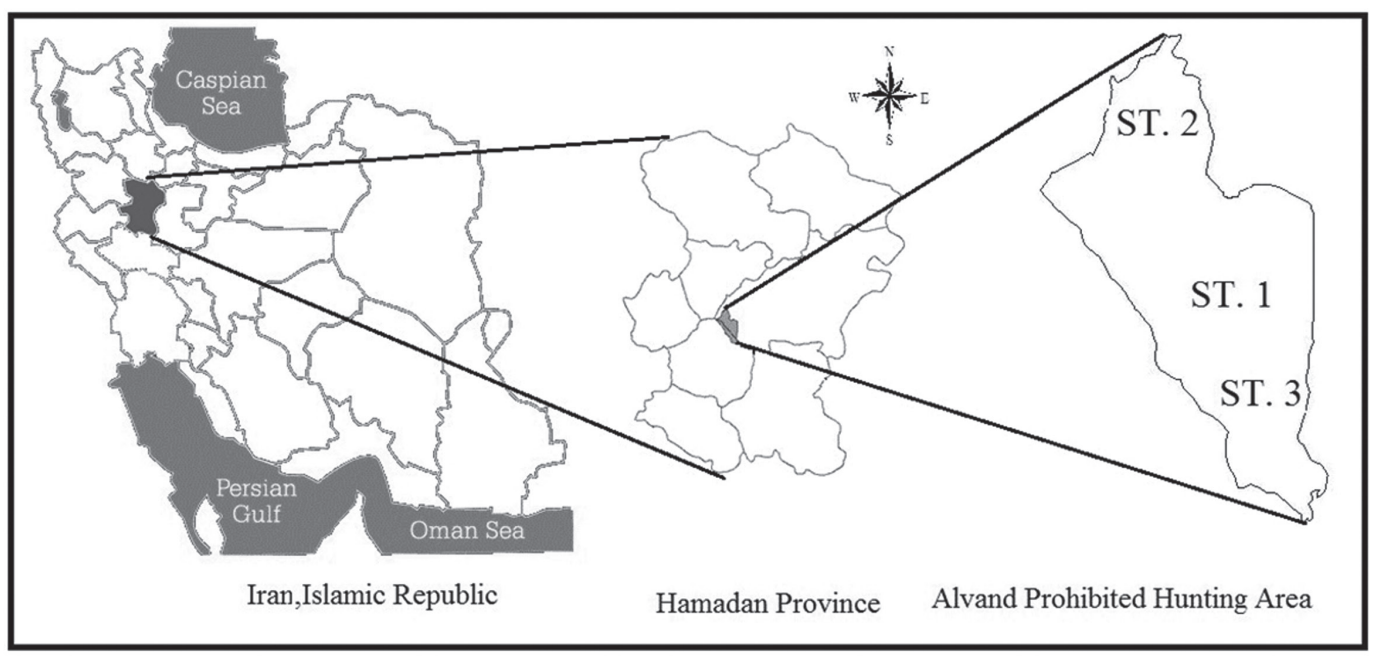

Figure 1. Location of the study area.

\section{MATERIALS AND METHODS}

\section{Study area}

The Alvand Mountains in Hamedan Province in western Iran are the main habitat of Nepeta crispa Wild (Mofarrah) in the world (Figure 1). The Alvand Mountains, part of the Zagros Mountains, encompass nine peaks covering 363 square kilometers; the tallest mountain is 3428 meters above sea level. 


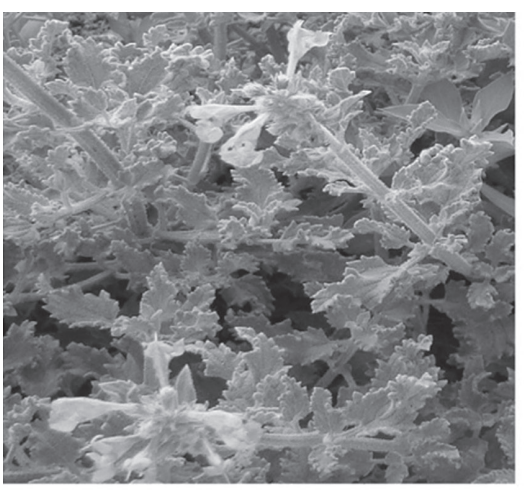

Mofarrah Plant

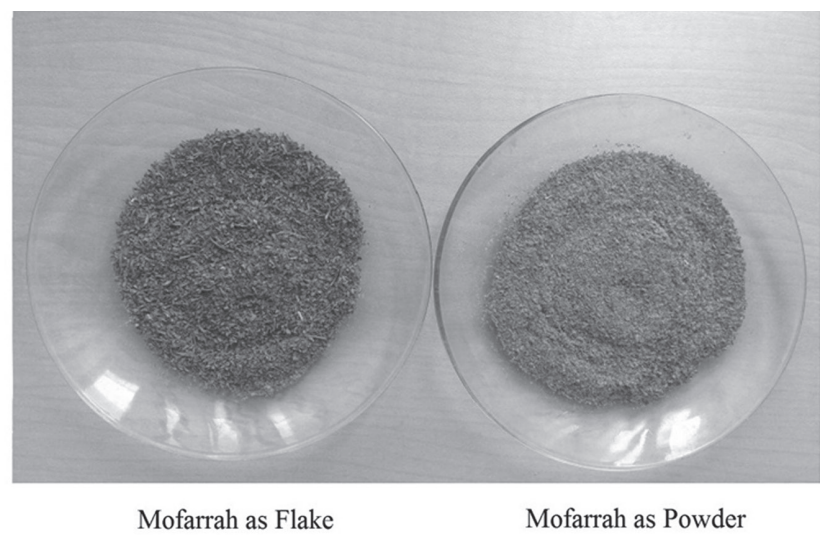

Mofarrah as Flake

Mofarrah as Powder

Figure 2. Pictures of the Mofarrah plant and its powder and flake form as used in this study.

\section{Collection of plant samples}

The aerial parts (leaf, flower, and stalk) of Nepeta crispa Wild were collected in June 2016 from three random sampling stations: one near Taarik-Daree (ST. 1), one near the village of Vafregin (ST. 2), and one near the village of Silvar (ST. 3) (Figure 1). Plant samples were identified and authenticated by Ramazan Kalvandi (scientific member of the Institute of Research and Education on Agriculture and Natural Resources in Hamedan, Iran) using standard procedures (Mozaffarian, 2006; Reyahi-khoram et al., 2012). The collected samples were cleaned using an air blower and dried in shadow (ambient temperature) for one week. Finally, the dried samples were crushed by a mechanical grinder and sieved through 0.125 , 0.5 , and $1 \mathrm{~mm}$ metal mesh to obtain fine powders (below $0.125 \mathrm{~mm}$ ) and flakes (between 0.5 and $1 \mathrm{~mm}$ ) (Figure 2) that were then packed in six zipped plastic bags (powder and flakes from each of the 3 sample locations). Ultraviolet radiation $(266 \mathrm{~nm}$ ) was used to sterilize the samples for 24 hours.

\section{Preparation of enriched yogurt samples}

The yogurt (4.6\% fat) used in this study was a commercial product produced from fresh bovine milk by Hamedan Pegah Co.

The sterilized powders and flakes were mixed with $125 \mathrm{~g}$ stirred yogurt using a mixer at the ratios of $0.0 \%$ (control), $0.25 \%, 0.5 \%$ and $0.75 \%(\mathrm{w} / \mathrm{w})$ and stored in a refrigerator (3$7^{\circ} \mathrm{C}$ ) for 48 hours before analysis. With a powder and flake form from three sampling stations each, this created 18 enriched samples, plus one non-enriched control.

\section{Chemicals and laboratory equipment}

To avoid inaccurate results, all reagents used in this work such as Sulfuric acid, Caustic Soda, Fenolftalein, Potassium Chromate, Amyl alcohol and Silver Nitrate were obtained commercially from Merck Co. (Germany) and used as received. Key laboratory equipment used in this study included Centrifuge (funke-gerber Co.); autoclaves (steel Co.); digital pH meter (Metrohm Co.); Bain Marie (Memmert Co.); incubator (Memmert Co.) and Laboratory Digital Scale (Sartorius Co.). 


\section{Physicochemical analysis}

Five quality parameters of the Mofarrah-enriched yogurt samples (MEYS) were measured: $\mathrm{pH}$, acidity, moisture, fat, and salt.

The $\mathrm{pH}$ value of each sample was measured using a digital pH meter (Hanna H18314, England). The acid content or Titratable Acidity (TA) was determined according to AOAC technique (Horwitz, 2000). Moisture content was determined by forced-draft oven method and fat content was determined using the Gerber method (Kleyn et al., 2001). Salt (\%) was measured using the Mohr titration method (ISIRI, 2008).

\section{Sensory evaluation}

All yogurt samples were removed from the refrigerator one hour prior to sensory evaluation and kept at room temperature $\left(22 \pm 2^{\circ} \mathrm{C}\right)$. The sensory analysis was performed by a panel consisting of 14 trained members ( 7 females and 7 males between 30-48 years old). A series of yogurt samples were prepared on plastic plates. Samples were coded and offered to the sensory panel along with a questionnaire. The questionnaire consisted of a five-point Hedonic scale for each attribute $(1=$ dislike extremely and $5=$ like extremely). Although a nine-point hedonic scale was desirable, we used a five-point scale for its ease and generality of implementation (Meilgaard et al., 2007; Cruz et al., 2011; Ayar and Gürlin 2014). The samples were rated for color, flavor, texture, taste, and overall acceptability.

\section{Statistical analysis}

The collected data was analyzed using SPSS version 16. Kolmogorov-Smirnov Test was used to test for normal distribution of the variables. One sample t-test was used to compare the means of the variables with the control sample. One-way ANOVA was used to assess the differences between groups.

\section{RESULTS}

\section{Mofarrah-enriched yogurt characteristics}

The results of the Kolmogorov-Smirnov Test indicated that the data was distributed normally. Based on the results, the average concentration of acidity and fat in the collected samples was $0.94(0.68)$ and $4.61(0.01)$ percent, respectively (Table 1). The results of onesample t-test showed that the means of acidity, $\mathrm{pH}$, and moisture of the Mofarrah-enriched yogurt differed significantly $(P<0.05)$ from the control (Table 1$)$.

Table 1. Physicochemical parameters of the Mofarrah-enriched yogurt compared to the control.

\begin{tabular}{lcccccc}
\hline Parameter & n & Mean & $\begin{array}{c}\text { Standard } \\
\text { error }\end{array}$ & $\begin{array}{c}\text { Test value } \\
\text { (control sample) }\end{array}$ & t & $\boldsymbol{P}$-value \\
\hline Acidity (\%) & 18 & 0.94 & 0.68 & 0.81 & 18.95 & $0.001^{*}$ \\
pH & 18 & 4.38 & 0.01 & 4.55 & 18.15 & $0.001^{*}$ \\
Moisture (\%) & 18 & 83.97 & 0.12 & 89.10 & 43.50 & $0.001^{*}$ \\
Salt (\%) & 18 & 0.67 & 0.13 & 0.65 & 1.40 & 0.18 \\
Fat (\%) & 18 & 4.61 & 0.01 & 4.60 & 1.72 & 0.10 \\
\hline
\end{tabular}

Note: *significant at $P<0.05$. 
One-way ANOVA showed no major differences between the yogurt samples enriched with either Mofarrah powder or flakes (Table 2). (Levene's test showed all obtained variances were homogeneous.)

Table 2. Comparison of parameters of Mofarrah-enriched yogurt as powders and flakes.

\begin{tabular}{|c|c|c|c|c|c|}
\hline \multirow{3}{*}{ Parameter } & \multicolumn{4}{|c|}{ Mofarrah-enriched yogurt } & \multirow{3}{*}{$P$-value } \\
\hline & \multicolumn{2}{|c|}{ Flake } & \multicolumn{2}{|c|}{ Powder } & \\
\hline & Mean & n & Mean & $\mathbf{n}$ & \\
\hline Acidity $(\%)$ & 0.94 & 9 & 0.94 & 9 & 0.558 \\
\hline $\mathrm{pH}$ & 4.39 & 9 & 4.37 & 9 & 0.908 \\
\hline Moisture (\%) & 83.97 & 9 & 89.10 & 9 & 0.715 \\
\hline Salt (\%) & 0.66 & 9 & 0.67 & 9 & 0.934 \\
\hline Fat $(\%)$ & 4.62 & 9 & 4.60 & 9 & 0.148 \\
\hline
\end{tabular}

Note: $* P$-value $>0.05$

\section{Differences based on sampling stations}

One-way ANOVA was used to compare the effects of sampling stations on the characteristics of the Mofarrah-enriched yogurt. (Levene's test showed all obtained variances were homogeneous.) In instances of multiple means comparisons, analysis of variance (ANOVA) was used, followed by post-hoc comparison using Tukey's test. The results are presented in Tables 3 and 4.

The acidity, $\mathrm{pH}$, and moisture content of the enriched yogurt using Mofarrah samples collected from ST. 1, ST. 2 and ST. 3 differed significantly $(P<0.05)$ (Table 3).

Table 3. The results of one-way ANOVA for each parameter from three sampling stations.

\begin{tabular}{|c|c|c|c|c|c|c|}
\hline Parameter & Source & df & $\begin{array}{l}\text { Sum of } \\
\text { squares }\end{array}$ & Mean square & $\mathbf{F}$ & $P$-value \\
\hline \multirow{3}{*}{ Acidity (\%) } & Between groups & 2 & 129.09 & 64.54 & 64.97 & \\
\hline & Within groups & 15 & 14.90 & 0.99 & & 0.001 \\
\hline & Total & 17 & 143.99 & & & \\
\hline \multirow{3}{*}{$\mathrm{pH}$} & Between groups & 2 & 0.014 & 0.007 & 8.63 & \\
\hline & Within groups & 15 & 0.012 & 0.001 & & 0.003 \\
\hline & Total & 17 & 0.026 & & & \\
\hline \multirow{3}{*}{ Moisture (\%) } & Between groups & 2 & 2.99 & 1.49 & 17.87 & \\
\hline & Within groups & 15 & 1.25 & 0.08 & & 0.001 \\
\hline & Total & 17 & 4.24 & & & \\
\hline \multirow{3}{*}{ Salt (\%) } & Between groups & 2 & 0.001 & 0.001 & 0.156 & \\
\hline & Within groups & 15 & 0.048 & 0.003 & & 0.857 \\
\hline & Total & 17 & 0.049 & & & \\
\hline \multirow{3}{*}{ Fat $(\%)$} & Between groups & 2 & 0.006 & 0.003 & 2.52 & \\
\hline & Within groups & 15 & 0.017 & 0.001 & & 0.115 \\
\hline & Total & 17 & 0.023 & & & \\
\hline
\end{tabular}


Tukey test determined which pairs of means were different; many differed significantly $(\mathrm{P}<0.05)$ (Table 4). This may be due to differences in geography and altitude between the sampling sites.

Table 4. Tukey test results for One-Way ANOVA for the Mofarrah that collected from sampling stations.

\begin{tabular}{lcccc}
\hline Parameter & $\begin{array}{c}\text { Sampling } \\
\text { stations }\end{array}$ & $\begin{array}{c}\text { Mean } \\
\text { difference }\end{array}$ & Standard error & P-value \\
\hline Acidity (\%) & St.1-St.2 & 0.02 & 0.57 & 0.01 \\
& St.1-St.3 & 0.06 & 0.57 & 0.001 \\
& St.2-St.3 & -0.02 & 0.57 & 0.01 \\
\hline pH & St.1-St.2 & 0.02 & 0.01 & 0.30 \\
& St.1-St.3 & 0.06 & 0.01 & 0.001 \\
& St.2-St.3 & 0.04 & 0.01 & 0.08 \\
\hline Moisture (\%) & St.1-St.2 & 0.03 & 0.17 & 0.98 \\
& St.1-St.3 & -0.85 & 0.17 & 0.001 \\
& St.2-St.3 & -0.85 & 0.17 & 0.001 \\
\hline
\end{tabular}

\section{Sensory properties}

The results of sensory evaluation and related scores of Mofarrah-enriched yogurt in the mentioned study have been presented in table 5. The responses from the 14 assays showed that the yogurt samples enriched with Mofarrah powder was accepted and it can be introduced as a new dairy product. The lowest scores were given to enriched yogurt were derived from Mofarrah flake rather than Mofarrah powder. The results showed that in the concentration of 0.25 and 0.5 percent of Mofarrah powder, there were significant difference in the taste, texture, color, and overall acceptability of the Mofarrah-enriched yogurt compared to the control sample $(P<0.05)$. Almost all different yogurt samples produced with Mofarrah powder showed better sensory quality than that of flake.

Table 5. Sensory evaluation of Mofarrah-enriched yogurt at different concentrations.

\begin{tabular}{|c|c|c|c|c|c|c|}
\hline \multirow[b]{2}{*}{ Type } & \multirow{2}{*}{$\begin{array}{c}\text { Enrichment } \\
\text { concentration } \\
(\%)\end{array}$} & \multicolumn{5}{|c|}{ 5-point scale* $($ mean \pm SD $)$} \\
\hline & & Taste & Flavor & Texture & Color & $\begin{array}{c}\text { Overall } \\
\text { acceptability }\end{array}$ \\
\hline \multirow[t]{4}{*}{ Powder } & 0.25 & $3.76 \pm 1.01^{\mathrm{c}}$ & $3.66 \pm 0.88^{b}$ & $4.27 \pm 0.78^{\mathrm{f}}$ & $4.23 \pm 0.72^{g}$ & $3.69 \pm 0.94^{\mathrm{m}}$ \\
\hline & 0.5 & $3.64 \pm 0.84^{c}$ & $4.00 \pm 0.55^{\mathrm{b}}$ & $4.35 \pm 0.63^{\mathrm{f}}$ & $4.47 \pm 0.61^{\mathrm{g}}$ & $3.78 \pm 0.69^{\mathrm{m}}$ \\
\hline & 0.75 & $3.23 \pm 0.72^{\mathrm{a}}$ & $3.23 \pm 0.72^{\mathrm{d}}$ & $3.84 \pm 0.80^{\mathrm{e}}$ & $3.46 \pm 0.52^{\mathrm{h}}$ & $3.23 \pm 0.83^{\mathrm{k}}$ \\
\hline & 0.25 & $3.35 \pm 0.74^{\mathrm{a}}$ & $3.35 \pm 0.74^{\mathrm{b}}$ & $4.00 \pm 0.78^{\mathrm{f}}$ & $3.92 \pm 0.61^{\mathrm{h}}$ & $3.28 \pm 0.72^{\mathrm{k}}$ \\
\hline \multirow[t]{2}{*}{ Flake } & 0.5 & $3.38 \pm 0.96^{\mathrm{a}}$ & $3.38 \pm 0.96^{\mathrm{b}}$ & $3.84 \pm 0.98^{\mathrm{e}}$ & $3.76 \pm 0.59^{\mathrm{h}}$ & $3.46 \pm 0.87^{\mathrm{k}}$ \\
\hline & 0.75 & $3.38 \pm 0.86^{\mathrm{a}}$ & $3.38 \pm 0.86^{\mathrm{b}}$ & $3.82 \pm 0.85^{\mathrm{e}}$ & $3.76 \pm 0.59^{\mathrm{h}}$ & $3.53 \pm 0.77^{\mathrm{k}}$ \\
\hline \multicolumn{2}{|c|}{ Control sample } & $3.00 \pm 0.78^{\mathrm{a}}$ & $3.78 \pm 0.69^{b}$ & $3.64 \pm 0.49^{\mathrm{e}}$ & $3.64 \pm 0.63^{\mathrm{h}}$ & $3.07 \pm 1.14^{\mathrm{k}}$ \\
\hline
\end{tabular}

Note: $* 1$ = dislike very much, $2=$ dislike moderately, $3=$ neither like nor dislike, $4=$ like moderately, and $5=$ like very much. Values with different superscript letters in a column differed significantly $(P<0.05)$ from the control sample. 


\section{DISCUSSION}

The current study investigated the effects of adding different levels of Mofarrah as a traditional herbal additive on the quality characteristics (acidity, moisture, $\mathrm{pH}$, fat, and salt) and sensory features of stirred yogurt. Mofarrah has been shown to have antioxidant properties (Ahmadvand et al., 2015). As such, if adding it to yogurt did not adversely affect the sensory characteristics of the enriched yogurt, it would offer a potentially important enriched food product. Sonboli et al. (2004) investigated the antimicrobial activity of essential oil of Mofarrah against seven bacteria and four fungi. The results showed that the oil of Moffarrah exhibited moderate to strong antibacterial activity against the tested bacteria and strong activity against the fungi. Based on the results, Bacillus subtilis and Staphylococcus aureus were the most sensitive to the compound.

The following sections discuss the physicochemical characteristics of the Mofarrahenriched yogurt.

\section{pH}

Controlling the $\mathrm{pH}$ of yogurt is important; if the $\mathrm{pH}$ of yogurt is less than about 4.6, the product should be stable for several weeks under refrigeration (Parker and Parker, 2004). The $\mathrm{pH}$ of the control yogurt was just less than 4.6. The $\mathrm{pH}$ of the Mofarrah-enriched yogurt was even less (4.4), and significantly different. Sengupta et al. (2014) also reported a decrease in the $\mathrm{pH}$ of enriched yogurt samples; the $\mathrm{pH}$ of watermelon juice enriched yogurt samples was 4.0. It can be concluded that, in some cases, traditional plant additives may provide substances that decrease the $\mathrm{pH}$ of yogurt.

\section{Acidity}

Titratable acidity of yogurt affects the shelf life and consumer acceptability of fermented dairy products (Yilmaz-Ersan and Kurdal, 2014). Acidity is specified frequently by lactic acid derived from the fermentation of lactose. Lactic acid is an important factor for preservation and tasting purposes of yogurt (Andronoiu et al., 2011). In contrast to $\mathrm{pH}$, the acidity of the Mofarrah-enriched samples increased significantly $(P<0.05)$ compared to the control due to acid formation. This increase in total yogurt acidity was a result of the higher growth of lactic acid bacteria in the Mofarrah-enriched yogurt. Despite the increase, the mean titratable acidity (0.94\%) of the Mofarrah-enriched yogurt was within the recommended values of the Institute of Standards and Industrial Research of Iran (ISIRI, 2008). Several studies have reported similar results (Najgebauer-lejko et al., 2014; Sengupta et al., 2014; Yilmaz-Ersan and Kurdal 2014).

\section{Moisture}

The mean moisture content of the Mofarrah-enriched yogurt $(84.0 \%)$ and control (89.1\%) samples differed significantly $(P<0.05)$. The Mofarrah powder or flakes increased the dry matter content of the yogurt. Ayar and Gürlin (2014) reported that the moisture content of yogurt decreased with added dietary fiber. 


\section{Salt}

To maintain the stability of stirred yogurt over its shelf life, about $0.7 \%$ of salt $(\mathrm{Nacl})$ is typically added. Based on World Health Organization (WHO) recommendations, total salt intake should not exceed six grams per day (WHO, 2003). Enriching the yogurt with Mofarrah did not significantly $(P>0.01)$ affect its salt content. A similar study was carried out on salted yogurt in Turkey by Berkay-Karaca and Kirdar (2016) which reported that salted yogurt was manufactured by the traditional technology. In this method, salt is added to yogurt at the ratio of $2 \mathrm{~g}$ salt/100gr (2\%) yogurt. Although salted yogurt is one of the most popular dairy products in some parts of Turkey, no governmental standards exist for salted yogurt in the country (Güler and Park 2009).

\section{Fat}

Fat content of yogurt ranges from 0.1 to over 10 percent. Enriching the yogurt with Mofarrah did not significantly $(P>0.01)$ affect its fat content compared to the control. While essential oils have been detected in different parts of Mofarrah (Sharma and Cannoo, 2013), their addition was not enough to affect the overall fat content of the enriched yogurt. Silva et al. (2014) showed that adding pequi to Greek yogurt increased its fat content.

\section{Sensory evaluation}

Enriching the yogurt with Mofarrah increased its overall sensory acceptability compared to the control. There were significant differences in the scores of texture, taste, color, and overall acceptability between the control sample and the samples treated with 0.25 or 0.50 percent of Mofarrah powder. Many researchers (Ayar and Gürlin, 2014; Sengupta et al., 2014; Izadi et al., 2015) have reported on the sensory properties of different enriched yogurts. Our study showed that adding Mofarrah to yogurt may yield a new enriched dairy product with good acceptability, too.

\section{ACKNOWLEDGEMENTS}

This research was supported by Islamic Azad University (Pharmaceutical Sciences Branch in Tehran) and Hamedan Pegah Co., an Iranian dairy industry company. The authors would like to thank the Department of Food Sciences \& Technology at Islamic Azad University; Mr. Doosty, the Head of the Hamedan Pegah Co.; and Mrs. Kagazchi, an expert in its R\&D department. 


\section{REFERENCES}

Ahmadvand, H., Amiri, H., and Dalvand, H. 2015. Antioxidant properties of hydro-alcoholic extract and extract of Nepeta crispa in Lorestan province. Hormozgan Medical Journal. 19(3):186-192.

Aline, L.D.B., Silva, R., Leandro, P.C., Caroline, N.A., Rita, K.A.G., Silva, M.C., Renata, S.L.R., Arellano, D.B., Sant'Ana, A.S., and Conte Junior C.A., et al. 2015. Quality parameters of probiotic yogurt added to glucose oxidase compared to commercial products through microbiological, physical-chemical and metabolic activity analyses. Food Research International. 77(3): 627-635. https://doi.org/10.1016/j. foodres.2015.08.017

Andronoiu, D.G., Botez, E., Mocanu, G.D., Nistor, O., and Nichiforescu, A. 2011. Technological research on obtaining a new product: Yoghurt with added walnuts and strawberries jam. Journal of Agroalimentary Processes and Technologies. 17(4): 452455.

Ayar, A., and Gürlin, E. 2014. Production and sensory, textural, physicochemical properties of flavored Spreadable yogurt. Life Science Journal. 11(4): 58-65.

Berkay-Karaca, O., and Sevgi Kirdar, S. 2016. Traditional dairy products in Hatay province. Journal of International Scientific Publications. 4(1): 339-447.

Cruz, A.G., Cadena, R.S., Faria, J.A.F., Oliveira, C.A.F., Cavalcanti, R.N., Bona, E., Bolini, H.M.A., and Silva, M.A.A.P.D. 2011. Consumer acceptability and purchase intent of probiotic yogurt with added glucose oxidase using sensometrics, artificial neural networks and logistic regression. International Journal of Dairy Technology. 64(4): 549-556. https://doi.org/10.1111/j.1471-0307.2011.00722.x

Cruz, A.G., Castro, W.F., Faria, J.A., Lollo, P.C., Amaya-Farfán, J., Freitas, M.Q., Rodrigues, D., Oliveira C.A., and Godoy, H.T. 2012. Probiotic yogurts manufactured with increased glucose oxidase levels: Postacidification, proteolytic patterns, survival of probiotic microorganisms, production of organic acid and aroma compounds, Journal of Dairy Science. 95(5): 2261-2269. https://doi.org/10.3168/jds.2011-4582

Cruz A.G., Castro, W.F., Faria, J.A.F., Bolini, H.M.A., Celeghini, R.M.S., Raices, R.S.L. Oliveira, C.A.F., Freitas, M.Q., Conte Júnior, C.A., and Mársico, E.T. 2013. Stability of probiotic yogurt added with glucose oxidase in plastic materials with different permeability oxygen rates during the refrigerated storage. Food Research International. 51(2): 723-728. https://doi.org/10.1016/j.foodres.2013.01.028

Güler, Z., and Park, Y.W. 2009. Evaluation of chemical and color index characteristics of goat milk, its yogurt and salted yogurt. Tropical and Subtropical Agroecosystems. 11(2009): $37-39$.

Horwitz, W. 2000. Official method of analysis of AOAC international. 17 $7^{\text {nd }}$ ed, AOAC International, Gaitherburg, Maryland.

Institute of Standards and Industrial Research of Iran (ISIRI). 2008. Yogurt Specifications and test methods. ISIRI no 695. $4^{\text {nd }}$ ed, ISIR Press, Tehran. (In Persian)

Izadi, Z., Nasirpour, A., Ali-Garoosi, G., and Tamjidi, F. 2015. Rheological and physical properties of yogurt enriched with phytosterol during storage. Journal of Food Science and Technology. 52(8): 5341-5346. https://doi.org/10.1007/s13197-014-1593-2 
Kleyn, D.H., Lynch, J.M., Barbano, D.M., Bloom, M.J., and Mitchell, M.W. 2001. Determination of fat in raw and processed milks by the Gerber method: collaborative study. Journal of AOAC International. 84(5):1499-1508.

Meilgaard, M., Civille, G.V., and Carr, B.T. 2007. Sensory evaluation techniques. $4^{\text {nd }}$ ed, CRC Press, Boca Raton.

Mohamadshahi, M., Veissi, M., Haidari, F., Shahbazian, H., Kaydani, G.A., and Mohammadi, F. 2014. Effects of probiotic yogurt consumption on inflammatory biomarkers in patients with type 2 diabetes. Bioimpacts. 4(2): 83-88. https://doi.org/10.5681/bi.2014.007

Mozaffarian. V.A. 2006. A dictionary of Iran plant names. Farhang Moaser publisher, Tehran, Iran.

Najgebauer-Lejko, D., Grega, T., and Tabaszewska, M. 2014. Yogurts with addition of selected vegetables: acidity, antioxidant properties and sensory quality. Acta Scientiarum Polonorum Technologia Alimentaria - Food Science. 13(1): 35-42.

Parker, J.N., and Parker, P.M. 2004. Yogurt (a medical dictionary, bibliography, and annotated research guide to internet references). ICON Group International Inc, San Diego.

Reyahi-khoram, M., Jafary, M., Bayati M., and Reyahi-khoram, R. 2012. Plants and animals diversity in Buqaty Mountain Area (BMA) in Hamadan Province, Iran. Biodiversitas. 13(4):190-194. https://doi.org/10.13057/biodiv/d130404

Sengupta, S., Chakraborty, A., and Bhowal, J. 2014. Production and evaluation of yogurt with watermelon (citrullus lanatus) juice. Journal of International Academic Research for Multidisciplinary. 2(5): 249-257.

Sharma, A., and Cannoo, D.S. 2013. Phytochemical composition of essential oils isolated from different species of genus nepeta of labiatae family: a review. Pharmacophore. 4(6): 181-211.

Silva, B.S., Resende, S.R., Souza, A.K., Silva, M.A.P., Placido, G.R., and Caliari, M. 2014. Sensory, physicochemical and microbiological characteristics of greek style yogurt flavored with pequi (Caryocar Brasiliense, Cambess). African Journal of Biotechnology. 13(37): 3799-3804. https://doi.org/10.5897/AJB2014.14053

Sonboli, A., Salehi, P., and Yousefzadi, M. 2004. Antimicrobial Activity and Chemical Composition of the Essential Oil of Nepeta crispa Willd from Iran. Zeitschrift für Naturforschung. 59(9, 10): 653-656.

World Health Organization (WHO). 2003. Food based dietary guidelines in the WHO European Region, Copenhagen.

Yilmaz-Ersan, L., and Kurdal, E. 2014. The production of set-type-bio-yogurt with commercial probiotic culture. International Journal of Chemical Engineering and Applications. 5(5): 402-408. https://doi.org/10.7763/IJCEA.2014.V5.418

Zomorodian, K., Saharkhiz, M.J., Rahimi, M.J., Shariatifard, S., Pakshir, K., and Khashei, R. 2013. Chemical composition and antimicrobial activities of essential oil of Nepeta Cataria L. against common causes of oral infections. Journal of Dentistry. 10(4):320337. https://doi.org/10.5402/2012/591953 